\title{
EXPLORING THE POTENTIAL OF EUDRAGIT FOR DEVELOPMENT OF MICROPARTICLES OF WATER-SOLUBLE DRUG USING QUALITY BY DESIGN APPROACH
}

\author{
SHAILESH SHARMA ${ }^{1}$, NIMRATA SETH ${ }^{2,3^{*}}$ \\ ${ }^{1}$ Pharmaceutical Research Department, ASBASJSM College of Pharmacy, Bela, Punjab, India, ${ }^{* 2}$ Department of Pharmaceutics, Rayat \\ Institute of Pharmacy, Railmajra, S. B. S. Nagar, Punjab, India, ${ }^{3}$ Inder Kumar Gujral, Punjab Technical University, Jalandhar, Kapurthala, \\ India \\ Email: nimrata.bela@gmail.com
}

Received: 26 Feb 2019, Revised and Accepted: 26 Apr 2019

\begin{abstract}
Objective: In the present protocol, employability of polymethacrylate polymer Eudragit RS100 for development of microparticles of water-soluble drug with desired values of response variables was investigated by central composite optimization design through the application of Design Expert $^{\circledR}$ software (Series DX10).

Methods: The microparticles were developed by emulsion solvent evaporation process employing Eudragit RS100. Two effective independent variables drug: polymer ratio and stirring speed were selected to assess performance prospective of Eudragit on mean particle size, entrapment efficiency, percent yield and drug release in $12 \mathrm{~h}$ of microparticles. Thirteen batches generated by the software were prepared and subjected to different characterization test parameters obligatory for the evaluation of formulation. Validation of optimization model and Statistical interpretation of results was done using Analysis of Variance (ANOVA).
\end{abstract}

Results: ANOVA indicated that the independent variables had a significant effect on response variables. Optimized formulation demonstrated close agreement amongst experimental and predicted responses with high desirability factor. In vitro drug liberation study for optimized formulation proposed a sustained release of drug from microparticles.

Conclusion: In conclusion, the optimization technique was imperative in indicating the efficient applicability of Eudragit RS100 polymer in controlling the drug release of hydrophilic drugs.

Keywords: Microparticles, Eudragit RS100, Optimization, Central composite design

(c) 2019 The Authors. Published by Innovare Academic Sciences Pvt Ltd. This is an open-access article under the CC BY license (http://creativecommons.org/licenses/by/4.0/) DOI: http://dx.doi.org/10.22159/ijap.2019v11i4.32816

\section{INTRODUCTION}

With the progressive research in formulation development for designing an optimum formulation with desired performance characteristics, several Statistical experimental designs such as factorial design, response surface methodology have emerged as powerful and systematic tools in multiple factor optimizations in fewer experimental trials [1-4]. Therefore, quality by design in this research protocol has been built-in by using response surface methodology by applying the most popular design of experiment, Central Composite Design (CCD); that describes optimal liaison among the process variables and responses for preparation of dosage form with desired performance characteristics [5-8].

Losartan Potassium is an angiotensin receptor blocker recommended as the first-line drug for the management of blood pressure (BP). The marketed immediate release dosage form of the drug exhibits low oral bioavailability owing to narrow therapeutic index and short half-life. Thus, to overcome shortcomings of the currently available formulations and control the BP with once a day therapy; the rationale of the research protocol undertaken encompasses the application of computer-aided technology to investigate the employability of polymethacrylate polymer Eudragit RS100 for controlling the drug release of hydrophilic drug, maximizing the percent yield, entrapment efficiency and hence efficacy of drug. Optimization technique has not been yet applied to investigate the study undertaken using low permeability polymer for a hydrophilic drug Losartan Potassium, the first choice drug for dealing complications associated with hypertension along with lowering of blood pressure. Eudragit RS100 is being increasingly employed for the development of oral sustained release microspheres. It is low permeability neutral It is low permeability neutral polymer that is insoluble in water and digestive juices but swells due to the presence of quaternary ammonium groups; thus, releases the drug by diffusion $[9,10]$. The aim of the study was to explore the applicability of polymethacrylate polymer Eudragit RS100 for development of microparticles of water-soluble drug with desired values of response variables by central composite optimization design through the application of Design Expert ${ }^{\circledR}$ software.

\section{MATERIALS AND METHODS}

\section{Materials}

Losartan potassium was obtained as a gratis sample from Theon Pharmaceuticals Pvt. Ltd., Baddi. Eudragit RS 100 was procured from Theon Pharmaceuticals Pvt. Ltd., Baddi. Isopropyl alcohol, Light liquid paraffin, n-hexane, methanol, dichloromethane were obtained from Loba Chemicals Private Limited. Talc, Span 80, potassium dihydrogen orthophosphate, sodium hydroxide and concentrated hydrochloric acid were purchased from SD Fine Chemicals.

\section{Methods}

\section{Design of experiment}

Central composite design (CCD) was employed using Design Expert ${ }^{\circledR}$ software (Trial Version DX10, Stat-Ease Inc., Minneapolis, USA) to prepare microspheres of Losartan potassium by emulsion solvent evaporation method using Eudragit RS 100. To optimize the formulation variables, factors selected for the study were drug: polymer ratio (A) and stirring speed (B) taken at five different levels viz.-alpha, low, center point, high-level and+alpha level as shown in table 1 . The response or dependent variables studied were mean particle size (Y1), drug entrapment efficiency (Y2), percent yield (Y3) and drug release at $12^{\text {th }}$ hour (Y4).

Statistical analysis was done using the software to generate linear, quadratic, cubic, Cross-product (2FI) models for the responses. The statistical interpretation of the results by Analysis of Variance (ANOVA) was done to establish which factors have a statistically significant effect on the response parameters and to ascertain validation of polynomial equations. The suitability of the model was resolute by the comparisons between the statistical parameters and the best fit model (suggested) 
was chosen based on reasonable concurrence between multiple correlation coefficients; adjusted $\mathrm{R}^{2}$ and predicted $\mathrm{R}^{2}$ (within 0.2 of each other), higher values of these coefficients (greater than $80 \%$ ), model pvalue (should be less than 0.05 ) and Lack-of fit measures. Contour and response plots resulting from the equations were developed utilizing the software. Numerical optimization and checkpoint formulations (CPF) method was applied to arrive at the optimized formulation through the desirability function approach.

Table 1: Central composite design (CCD) matrix, actual or coded values

\begin{tabular}{|c|c|c|c|c|c|c|}
\hline \multirow[t]{2}{*}{ S. No. } & \multirow[t]{2}{*}{ Independent variables } & \multicolumn{5}{|c|}{ Coded and Actual levels } \\
\hline & & $\begin{array}{l}(-1.41421) \\
\text { Alpha level }\end{array}$ & -1 (Low) & $\begin{array}{l}0 \\
\text { (Middle) }\end{array}$ & $\begin{array}{l}1 \\
\text { (High) }\end{array}$ & $\begin{array}{l}(+1.41421) \\
\text { Alpha level }\end{array}$ \\
\hline 1. & Drug: Polymer ratio $(\mathrm{w} / \mathrm{w}), \mathrm{A}$ & 1.58 & $1: 2$ & $1: 3$ & $1: 4$ & 4.41 \\
\hline 2. & Stirring Speed (rpm), B & 717 & 800 & 1000 & 1200 & 1282 \\
\hline
\end{tabular}

\section{Preparation of microspheres}

The microspheres of Losartan potassium were prepared by varying the drug and polymer ratio and co-dissolving them into a mixture of methanol-acetone $(1: 1 \mathrm{v} / \mathrm{v})$ with continuous stirring using Remi's mechanical stirrer (Model: RQ-121/D). The resultant dispersion was slowly introduced into light liquid paraffin containing span 80 (final concentration $1 \% \mathrm{w} / \mathrm{w}$ ) as an emulsifying agent). The drug: polymer ratio and stirring speed were varied as per CCD experimental design. Light liquid paraffin was decanted and the microparticles were recovered by filtration followed by washings with $n$-hexane to remove paraffin. The resulting microparticles were dried at room temperature for $24 \mathrm{~h}$ and evaluated for various in vitro parameters [11-14].

\section{Optimization and validation model}

Diverse batches of losartan potassium loaded eudragit microparticles were prepared as per the CCD and a total of 13 runs were presented by the Design Expert ${ }^{\circledR}$ software. The design matrix is shown in table 2 .

Table 2: Central composite design matrix, the observed responses

\begin{tabular}{|c|c|c|}
\hline \multirow[t]{2}{*}{ Runs } & \multicolumn{2}{|l|}{ Independent variables } \\
\hline & Drug: polymer ratio (A), w/w & Stirring speed (B), rpm \\
\hline 1. & 1 & -1 \\
\hline 2. & 0 & 0 \\
\hline 3. & -1 & 1 \\
\hline 4. & 1 & 1 \\
\hline 5. & 0 & 0 \\
\hline 6. & -1 & -1 \\
\hline 7. & 0 & -1.41421 \\
\hline 8. & -1.41421 & 0 \\
\hline 9. & 1.41421 & 0 \\
\hline 10. & 0 & 0 \\
\hline 11. & 0 & 0 \\
\hline 12. & 0 & 0 \\
\hline 13. & 0 & 1.41421 \\
\hline
\end{tabular}

The response (Yi) in each testing run was calculated by carrying out a regression analysis to develop equations for (Y1-Y4).

$Y i=\beta_{0} \beta_{1} A+\beta_{2} B+\beta_{3} A B+\beta_{4} A^{2}+\beta_{5} B^{2} E q$. (1)

Where, $Y$ is the estimated response of dependent variables,

$\beta_{0}$ is the intercept of the polynomial equation,

$\beta_{1-5}$ represents an estimated regression coefficient for factor $A$ and $B$

$\mathrm{AB}$ are the coefficients corresponding interaction and

$\mathrm{A}^{2}$ and $\mathrm{B}^{2}$ represent the quadratic effects $[8,15]$.

\section{Evaluation of microparticles}

Microparticles were evaluated for micromeritic properties by measuring the angle of repose, bulk density, tapped density, Carr's index and Hausner ratio using standard reported procedures. The average particle size of microspheres was analyzed by simple optical microscopy method using the ocular lens and stage micrometer. Approximately 300 microspheres were counted and the average equivalent spherical diameter was measured [16-18]. The drug entrapment efficiency was determined by taking accurately weighed microspheres equivalent to $25 \mathrm{mg}$ of losartan potassium and crushed to obtain a fine powder. The powder was dissolved in 100 $\mathrm{ml}$ of phosphate buffer $\mathrm{pH} 6.8$ in a conical flask. The solution obtained was filtered, suitably diluted and analyzed spectrophotometrically using Ultraviolet-Visible (UV-VIS) double beam spectrophotometer at $235 \mathrm{~nm}$. All the readings were taken in triplicate. Drug content was determined by the following formula:
Drug entrapment efficiency (\%) $=\frac{\text { Conc.of drug present in microspheres }}{\text { Amount of Drug initially Taken }} \mathrm{X} 100$ Eq. (2)

The microspheres obtained were weighed accurately and the percentage yield was calculated as the weight of losartan potassium microspheres recovered from each batch in relation to the sum of starting material [19-21].

$$
\text { Yield (\%) }=\frac{\text { Actual weight of the microspheres obtained }}{\text { Total weight of the excipients and drug }} \times 100 \mathrm{Eq} \text {. }
$$

On the basis of the optimization and validation model, the optimized formulation was selected for further analysis. Fourier Transform Infra-Red (FTIR) spectra of pure drug and optimized formulation were recorded using ATR-FTIR spectrophotometer to investigate any possible interaction between drug-loaded microspheres. The morphology of optimized formulation of microspheres was examined by Scanning electron microscope analysis using SEM; Jeol JSM-6400, Japan. To analyze the existence condition of Losartan Potassium (LP) in the microspheres, Differential Scanning Calorimetry (DSC) of the LP microspheres was carried out.

In vitro drug release study was carried out in simulated physiological $\mathrm{pH} 6.8$ using USP Type I dissolution apparatus at $37 \pm 0.5{ }^{\circ} \mathrm{C}$ to calculate the amount of drug released from microspheres. The assembly was operated at $100 \mathrm{rpm}$ under sink conditions thereby maintaining the constant dissolution volume of $900 \mathrm{ml}$. The sample was withdrawn at suitable time intervals and replaced with a fresh equal volume of dissolution medium. The samples withdrawn were analyzed using double beam UV-VIS spectrophotometer at $235 \mathrm{~nm}$ to determine the percent drug released. The dissolution data so obtained were fitted to various 
drug-release kinetic models such as Zero order, First order, Higuchi and Korsmeyer Peppas model. The release kinetics was assessed by comparing the values of the regression coefficient $\left(\mathrm{r}^{2}\right)[22,23]$.

\section{RESULTS}

The investigated response variables for the conducted experimental trials are shown in table 3.

Table 3: Central composite design matrix, the observed responses

\begin{tabular}{|c|c|c|c|c|c|c|}
\hline \multirow[t]{2}{*}{ Runs } & \multicolumn{2}{|c|}{ Independent variables } & \multicolumn{4}{|c|}{ Dependent variables } \\
\hline & $\begin{array}{l}\text { Drug: polymer } \\
\text { ratio (A), w/w }\end{array}$ & $\begin{array}{l}\text { Stirring speed } \\
\text { (B), rpm }\end{array}$ & $\begin{array}{l}\text { Mean particle size } \\
(\mathrm{Y} 1),(\mu \mathrm{m})^{*}\end{array}$ & $\begin{array}{l}\text { Entrapment efficiency } \\
(\mathrm{Y} 2),(\%)^{*}\end{array}$ & $\begin{array}{l}\text { Percent yield } \\
\text { (Y3), (\%)* }\end{array}$ & $\begin{array}{l}\text { Drug rel at } 12^{\text {thh }} \\
(Y 4),(\%)^{*}\end{array}$ \\
\hline 1. & 1 & -1 & $169.2 \pm 1.23$ & $71.37 \pm 1.23$ & $65.49 \pm 0.74$ & $67.96 \pm 2.62$ \\
\hline 2. & 0 & 0 & $121.26 \pm 2.38$ & $79.73 \pm 1.09$ & $76.49 \pm 1.73$ & $76.55 \pm 1.29$ \\
\hline 3. & -1 & 1 & $102.28 \pm 2.03$ & $70.39 \pm 1.54$ & $75.15 \pm 2.47$ & $75.94 \pm 0.47$ \\
\hline 4. & 1 & 1 & $140.66 \pm 0.86$ & $74.18 \pm 1.25$ & $74.59 \pm 1.74$ & $74.69 \pm 1.20$ \\
\hline 5. & 0 & 0 & $120.48 \pm 1.01$ & $78.44 \pm 0.89$ & $76.68 \pm 1.26$ & $75.35 \pm 1.40$ \\
\hline 6. & -1 & -1 & $119.69 \pm 1.03$ & $69.3 \pm 2.26$ & $77.98 \pm 1.74$ & $76.68 \pm 0.82$ \\
\hline 7. & 0 & -1.41421 & $145.69 \pm 0.36$ & $73.05 \pm 0.63$ & $70.26 \pm 1.23$ & $64.19 \pm 2.95$ \\
\hline 8. & -1.41421 & 0 & $100.96 \pm 1.47$ & $67.95 \pm 1.78$ & $76.85 \pm 2.05$ & $77.19 \pm 2.40$ \\
\hline 9. & 1.41421 & 0 & $163.79 \pm 1.59$ & $73.67 \pm 1.78$ & $67.95 \pm 0.86$ & $73.89 \pm 1.23$ \\
\hline 10. & 0 & 0 & $120.03 \pm 1.15$ & $79.1 \pm 0.83$ & $67.45 \pm 0.55$ & $80.64 \pm 2.29$ \\
\hline 11. & 0 & 0 & $119.49 \pm 1.33$ & $80.74 \pm 1.02$ & $69.64 \pm 1.32$ & $66.55 \pm 3.54$ \\
\hline 12. & 0 & 0 & $120.55 \pm 0.38$ & $78.88 \pm 1.90$ & $65.29 \pm 1.96$ & $80.95 \pm 2.78$ \\
\hline 13. & 0 & 1.41421 & $113.68 \pm 2.59$ & $75.96 \pm 2.44$ & $62.56 \pm 1.08$ & $79.25 \pm 1.40$ \\
\hline
\end{tabular}

*All values are expressed as mean $\pm \mathrm{SD}, \mathrm{n}=6$ (for standard deviation)

\section{Statistical data analysis and model validation}

Linear, quadratic, cubic, Cross-product (2FI) models were generated by the software for the responses. The ANOVA for the regression mode demonstrated that the quadratic model was greatly significant as indicated by the p-value, $<0.0001$ and $\mathrm{R}^{2}$ near to 1 . The equations generated (as shown in table 4) were used to quantify the response data. Positive sign of coefficient indicated synergistic effect (increase in response) while negative sign indicated antagonistic effect (decrease in response values) as the factor was changed from low to a high level [24].

Table 4: Equations for quadratic model

\begin{tabular}{|c|c|c|c|c|c|c|}
\hline Response & Intercept & $\mathbf{A}$ & B & AB & $A^{\wedge} 2$ & $\mathrm{~B}^{\wedge} 2$ \\
\hline Mean Particle Size (Y1) & 120.362 & 22.0931 & -11.4024 & -2.7825 & 6.48837 & 5.14337 \\
\hline p-value & & $<0.0001$ & $<0.0001$ & 0.0019 & $<0.0001$ & $<0.0001$ \\
\hline Entrapment Efficiency (Y2) & 79.378 & 1.74366 & 1.00192 & 0.43 & -4.62087 & -2.77337 \\
\hline p-value & & 0.0020 & 0.0286 & 0.4318 & $<0.0001$ & 0.0002 \\
\hline Percent Yield (Y3) & 76.63 & 1.13 & 1.96 & 0.50 & -6.14 & -2.96 \\
\hline $\mathrm{p}$-value & & 0.0322 & 0.0024 & 0.4338 & $<0.0001$ & 0.0003 \\
\hline Drug rel at $12^{\text {th }} \mathrm{h}(\mathrm{Y} 4)$ & 76.342 & -6.04726 & -0.0735786 & -0.275 & -2.056 & -0.771 \\
\hline $\mathrm{p}$-value & & $<0.0001$ & 0.8618 & 0.6478 & 0.0022 & 0.1210 \\
\hline
\end{tabular}

The values for mean particle size showed a broad variation ranging from $100.96 \pm 1.47$ to $169.20 \pm 1.23 \mu \mathrm{m}$. The data as well as model evidently signified that the independent variables drug: polymer ratio $(A)$ and stirring speed $(B)$, their interaction term $(A B)$ and the quadratic terms $\left(A^{2}\right.$ and $\left.B^{2}\right)$ showed a significant effect on particle size (Y1), $\mathrm{p}<0.0001$. Expanding the drug: polymer proportion brought about the mean microparticle size to move towards a higher value, as indicated by the positive coefficients of A. On the other hand, mean particle size decreased with increase in stirring speed as indicated by the negative coefficients of $B, p<0.0001$. The values of drug entrapment efficiency (Y2) for the various experimental runs ranged between $67.95 \pm 1.78$ to $80.74 \pm 1.02 \%$. With the increase in independent variables, the entrapment efficiency increased up to the middle level than it started decreasing on further increase in A and
B. The yield values for all the runs demonstrated wide difference going from a lowest of $62.56 \pm 1.08$ to a highest of $77.98 \pm 1.74 \%$. In-vitro drug release data for all the experimental runs ranged between $64.19 \pm 2.62$ to $80.95 \pm 2.78 \%$.

Validation by checkpoint formulation (CPF) and Numerical optimization

To approve the model equations resulting from regression analysis, Numerical optimization method was applied to arrive at the optimized formulation through the desirability function approach. The accompanying blend of independent variables (CPF) was recommended by the software with the desirability function of 0.840 . Table 5 shows the predicted and experimental values of both the responses and the value of residuals obtained with error value less than 1.

Table 5: Validation of model with CPF and numerical optimization

\begin{tabular}{|c|c|c|c|c|c|c|}
\hline \multirow[t]{2}{*}{ S. No. } & \multicolumn{2}{|c|}{ Composition } & \multirow[t]{2}{*}{ Response variables } & \multirow[t]{2}{*}{ Experimental values } & \multirow[t]{2}{*}{ Predicted values } & \multirow[t]{2}{*}{ Residuals } \\
\hline & $A(w / w)$ & B (rpm) & & & & \\
\hline \multirow[t]{4}{*}{ CPF } & 2.75 & 1065 & Mean particle Size $(\mathrm{Y} 1),(\mu \mathrm{m})$ & $113.17 \pm 0.86$ & 112.41 & -0.76 \\
\hline & & & Entrapment efficiency (Y2), (\%) & $78.39 \pm 1.06$ & 78.67 & -0.28 \\
\hline & & & Percent Yield (Y3), (\%) & $77.15 \pm 0.58$ & 76.22 & 0.93 \\
\hline & & & Drug Rel at $12^{\text {th }} \mathrm{h}(\mathrm{Y} 4),(\%)$ & $78.58 \pm 1.43$ & 77.61 & 0.67 \\
\hline
\end{tabular}

$\mathrm{n}=6$ (for standard deviation), to graphically envision the effect of formulation/operation variables on the output variables, Contour and Response surface plot were constructed using the software as shown in fig. 1 . 


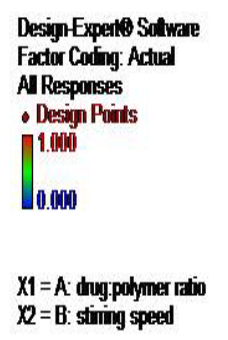

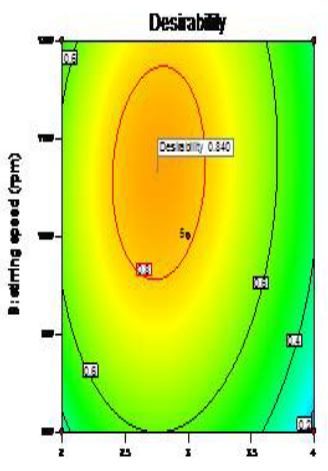

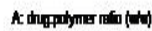

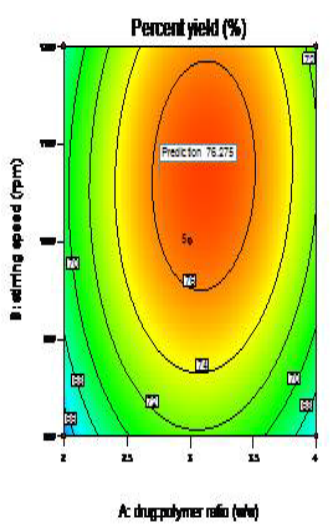

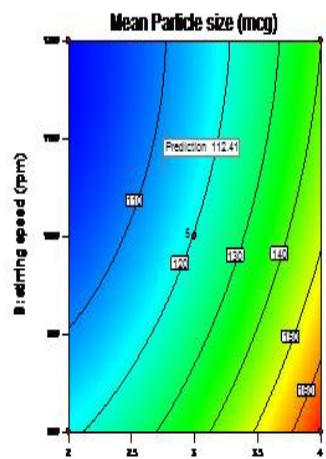

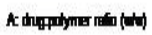

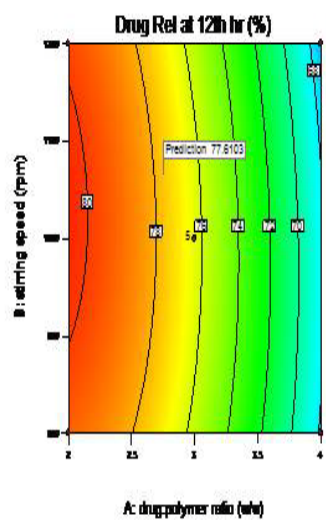

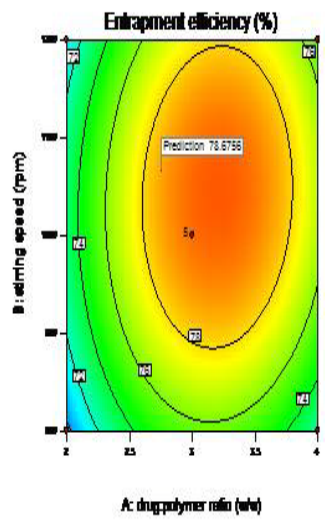

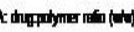

Fig. 1: 2D contour and 3D response surface for optimized formulation

\section{Evaluation of microparticles}

Formulations of microspheres indicated good flow properties as was observed from the various characteristics evaluation parameters. The values for the angle of repose lied between $26.78^{\circ} \pm 0.64$ to 34.57 ${ }^{\circ} \pm 0.36$, Carr's compressibility index for various formulations was in range 12.03 to $23.08 \%$ while the data obtained for Hausners ratio ranged between 1.14 to 1.30 . The results indicated good to fair flow properties of microspheres. FTIR studies of losartan potassium, (A) and optimized formulation (B) were compared for any kind of unwanted significant interaction. FTIR spectra did not show any significant changes in the principal peaks of pure drug indicating an absence of chemical interaction between the drug and polymer (fig. 2). The comparison of spectral assignment for pure drug and mixture has been shown in table 6. The shape of optimized formulation was examined by Scanning electron microscope (SEM) analysis. The study (fig. 3) revealed that the discrete, uniformly shaped spherical microspheres were obtained. The DSC trace of LP showed a sharp thermographic peak at 274.8 and a broad endothermic peak at the same temperature as shown in fig. 4 and 5 respectively.

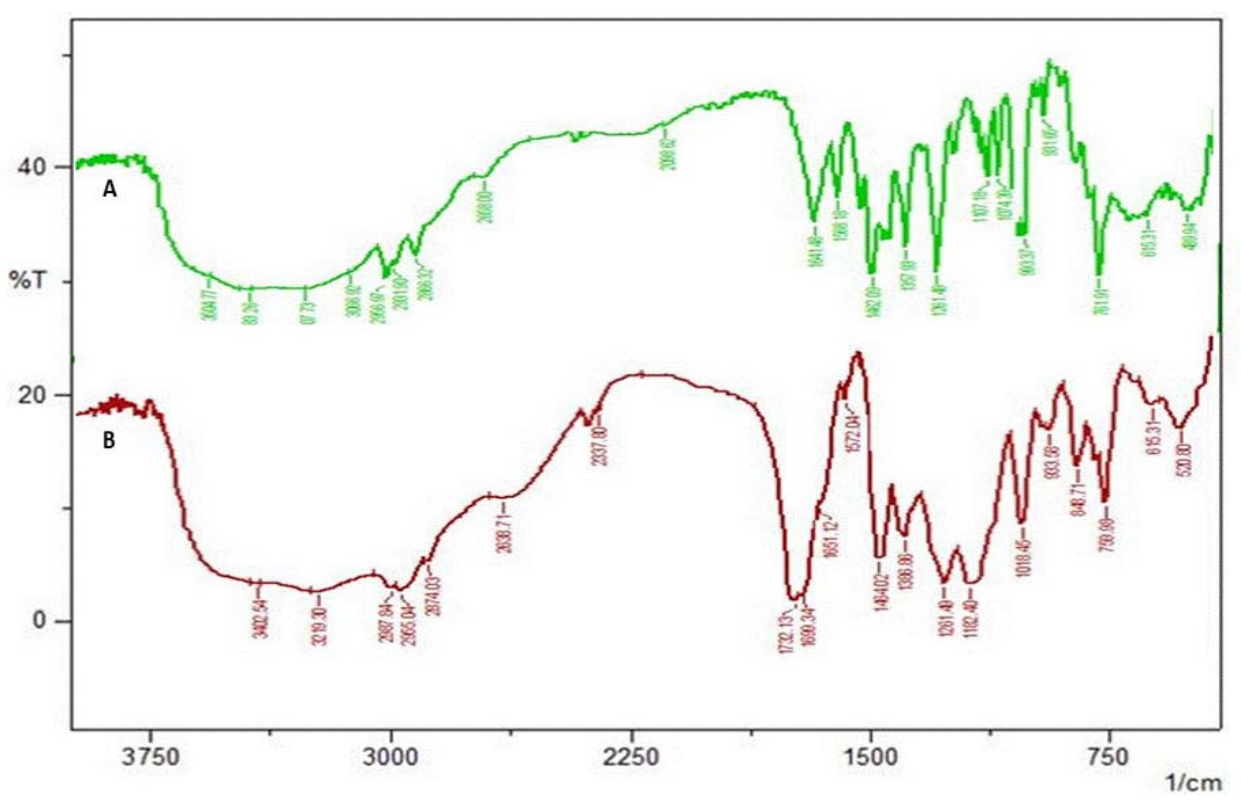

Fig. 2: FTIR spectra of (A) Losartan potassium and (B) optimized formulation 
Table 6: Spectral assignment of losartan potassium and optimized formulation

\begin{tabular}{|c|c|c|c|}
\hline S. No. & Wave number $\left(\mathrm{cm}^{-1}\right)$ losartan potassium & Wave number $\left(\mathrm{cm}^{-1}\right)$ optimized formulation & Vibration mode \\
\hline 1 & 3000 & 2987.98 & C-H stretching \\
\hline 2 & 2960 & 2956.14 & Distinct band sym $\mathrm{CH}_{3}$ group \\
\hline 3 & 1458 & 1459.60 & Stretching aromatic $\mathrm{C}-\mathrm{C}$ ring \\
\hline 4 & 3189.8 & 3197.48 & Stretching $\mathrm{O}-\mathrm{H}$ \\
\hline 5 & 841.5 & 763.61 & Stretching $\mathrm{C}-\mathrm{Cl}$ \\
\hline
\end{tabular}

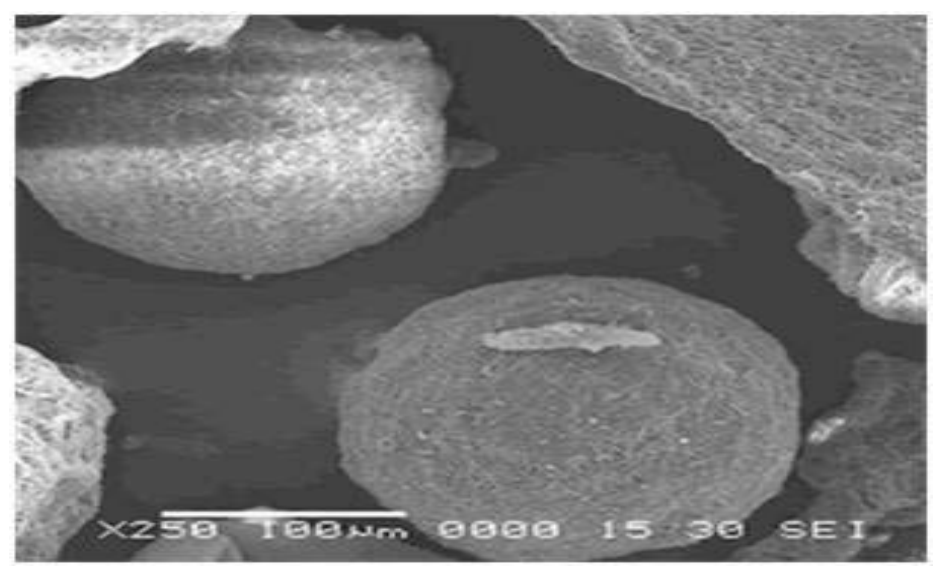

Fig. 3: Scanning electron microscope analysis of optimized microsphere formulation

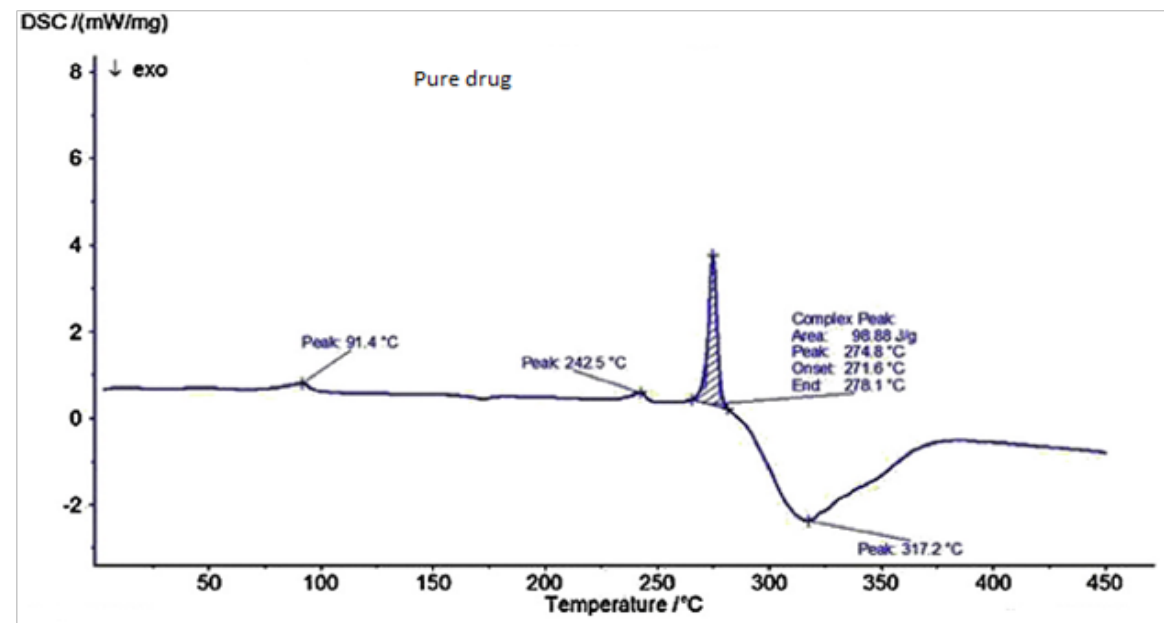

Fig. 4: Differential scanning calorimetric analysis of pure drug (Losartan Potassium)

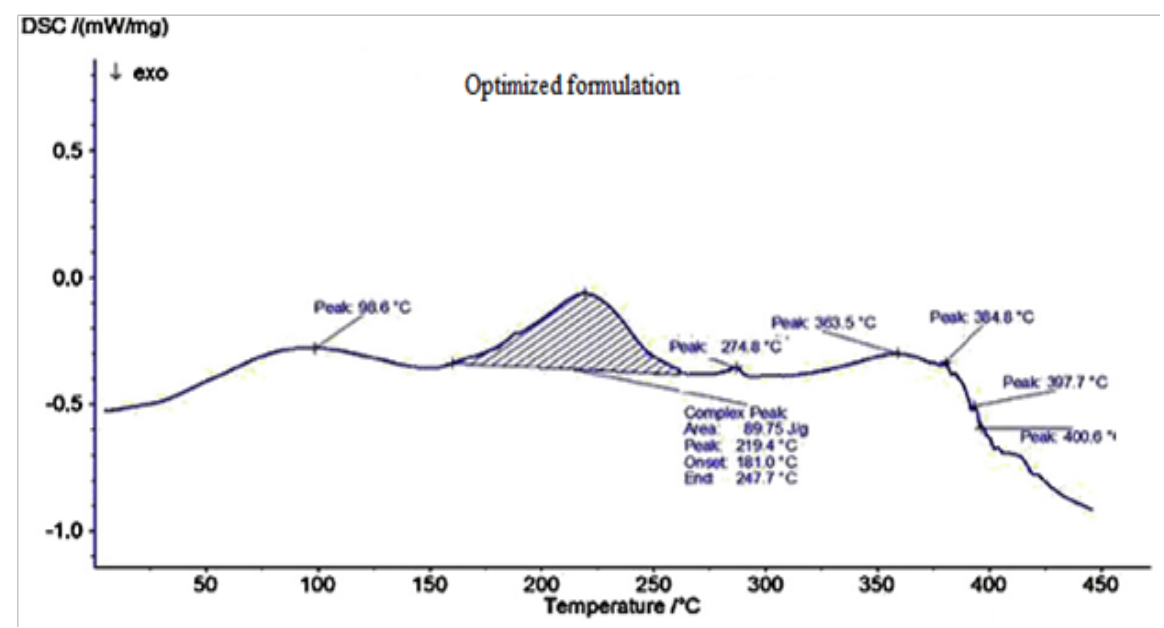

Fig. 5: Differential scanning calorimetric analysis of optimized formulation 
The dissolution data so obtained was then fitted to various drugrelease kinetic models. The release mechanism was assessed by comparing the values of the regression coefficient $\left(\mathrm{r}^{2}\right)$ as shown in table 7. The value of the regression coefficient was found to be higher for Korsmeyer-Peppas model i.e. $r^{2}=0.976$. The various dissolution models for optimized formulation have been shown in fig. 6 .

Table 7: Regression data for various dissolution kinetic models

\begin{tabular}{llllll}
\hline S. No. & Parameter & Dissolution kinetic model & & \\
\cline { 3 - 6 } & & Zero order & First order & Higuchi model & Koresmeyer peppas model \\
\hline 1 & Regression equation & $\mathrm{y}=7.770 \mathrm{x}-2.737$ & $\mathrm{y}=-0.065 \mathrm{x}+2.077$ & $\mathrm{y}=27.98 \mathrm{x}-19.78$ & $\mathrm{y}=1.231 \mathrm{x}+0.660$ \\
2 & Correlation coefficient $\left(\mathrm{r}^{2}\right)$ & 0.959 & 0.944 & 0.878 & 0.976 \\
\hline
\end{tabular}

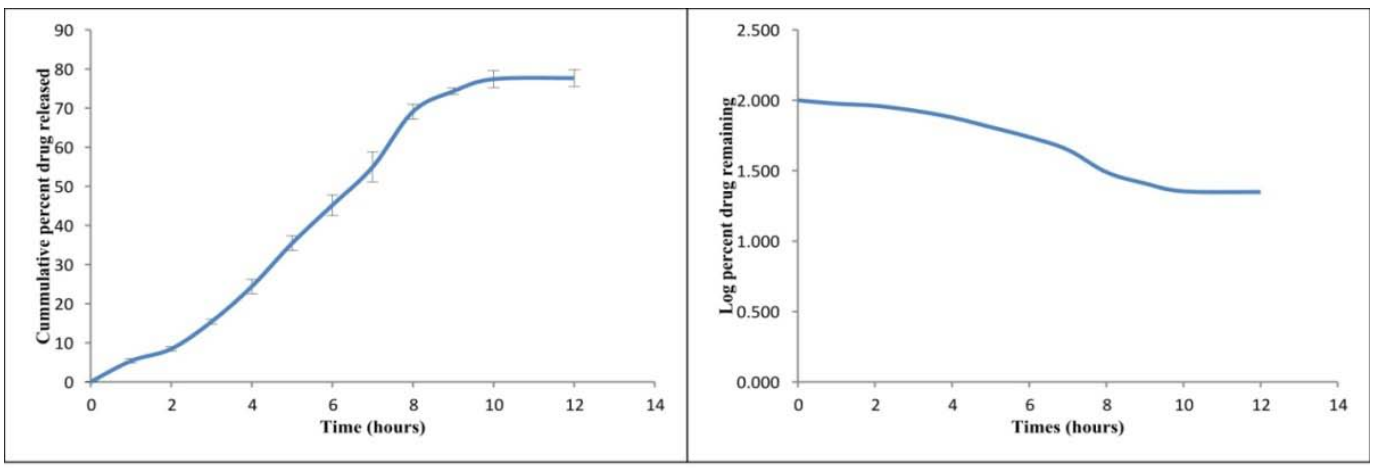

(a)

(b)

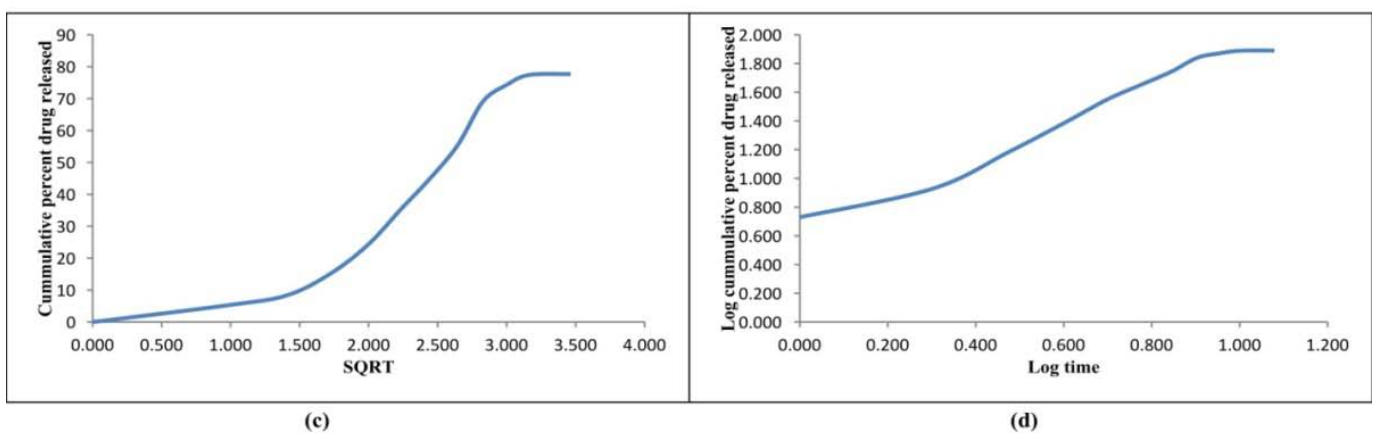

Fig. 6: Dissolution models for optimized formulation (a) Zero order, (b) First order, (c) Higuchi model and (d) Koresmeyer peppas model

\section{DISCUSSION}

Microspheres of losartan potassium were prepared using a mixed solvent system and light liquid paraffin as the dispersed phase and continuous phase respectively to facilitate the formation of microparticles by emulsion solvent evaporation method with Eudragit RS100. Judicial selection of solvent system was done based on their dielectric constants. The solvents having dielectric constant above 10 and below 40 reflect poor miscibility in light liquid paraffin; therefore, paraffin was preferred as a continuous phase in which both losartan potassium and Eudragit RS100 are scantily soluble [25]. Span 80 was supplemented as an emulsifier to prevent coalescence of droplets during solvent evaporation. Emulsion solvent evaporation was found reliable for preparation of microparticles of losartan potassium.

The data generated by statistical experimental design clearly signified that the independent variables (A) and (B), their interaction term $(\mathrm{AB})$ and the quadratic terms $\left(\mathrm{A}^{2}\right.$ and $\left.\mathrm{B}^{2}\right)$ showed a significant effect on response variables (Y1-Y4); $(\mathrm{p}<0.0001)$. Initially, expanding the drug: polymer proportion brought about the mean microparticle size to move towards a higher value, as indicated by the positive coefficients of A, which can be attributed to the fact that higher polymer concentration produced more viscous dispersion and therefore, shearing effect was less at impeded circulation that formed larger droplets $[17,18]$. Microscopic analysis of formulations revealed that stirring speed plays an important role in determining the size and shape of microparticles. Mean particle size decreased with increase in stirring speed producing uniform spherical microparticles.
On the other hand, in case of entrapment efficiency (Y2), it was experiential that with the increase in independent variables, the former increased up to the middle level than it started decreasing on further increase in A owing to the fact that an increase in polymer concentration in a fixed volume of organic solvent resulted in augmenting the entrapment efficiency.

In case of percent yield (Y3), it was observed that as the drug: polymer ratio was increased, the total material in the dispersed phase increased. Finer particles formed during the preparation of microparticles tend to coalesce to give bigger particles with better percent yield. The model applied for drug release at $12^{\text {th }}$ hour (Y4) showed that as the drug: polymer ratio was varied towards higher side, the drug release retarded from the formulations as diffusional path length for drug release increased while with increase in stirring speed the interfacial area per unit volume increased, so, the drug release also increased $[8,26-28]$.

The ANOVA for the regression model demonstrated that the quadratic model was highly significant as indicated by the p-value. The reasonably lower values of residual between predicted and observed experimental values for all the four response variables indicated a pragmatic agreement between the predicted and trial values were observed. Hence, the mathematical model was well fitted. Numerical optimization technique using the desirability function approaching 1 for obtaining optimized formulation indicated desirable range for independent variables $\mathrm{A}$ and $\mathrm{B}$ to get the optimum response for further investigation. SEM study revealed that the discrete, uniformly shaped spherical microspheres were 
obtained. DSC results indicated that there is no change of LP in the pure state, formulation of microspheres. LP existed in an amorphous as a molecular dispersion in the polymeric matrix. In vitro drug liberation study for optimized formulation proposed a sustained release of drug from microparticles indicating the efficient applicability of Eudragit RS100 polymer in controlling the drug release of hydrophilic drugs.

\section{CONCLUSION}

In the present research, the statistical experimental design approach was undertaken for preparing microparticles of losartan potassium by modified solvent evaporation process using Eudragit RS100 as polymer. From the results of various in vitro evaluation parameters, it was concluded that optimization plays an important role in designing of dosage forms with desired performance characteristics.

\section{ACKNOWLEDGMENT}

The authors are grateful to Inder Kumar Gujral, Punjab Technical University, Jalandhar for providing the necessary platform for carrying out the research project.

\section{CONFLICT OF INTERESTS}

No conflict of interest associated with this work

\section{REFERENCES}

1. Nagarwal RC, Srinatha A, Pandit JK. In-situ forming formulation: Development, evaluation and optimization using $3^{3}$ factorial design. AAPS PharmSciTech 2009;10:977-84

2. Bas D, Boyaci IH. Modeling and optimization: usability of response surface methodology. J Food Eng 2007;78:836-45.

3. Chopra S, Patil GV, Motwani SK. Release modulating hydrophilic matrix systems of Losartan potassium: optimization of formulation using statistical experimental design. Eur J Pharm Biopharm 2007;66:73-82.

4. Kehoe S, Kilcup N, Boyd D. Evaluation of cytotoxicity for novel composite microspheres: material optimization by response surface methodology. Matter Lett 2012;86:13-7.

5. Martins SA, Prazerers DM, Fonseca LP, Monteiro GP. Application of central composite design for DNA hybridization onto magnetic micropsheres. Anal Biochem 2009;391:17-23.

6. Montgomery DC. Introduction to statistical quality control. 6th ed. John Wiley and Sons: New York; 2008.

7. Das SK, Yuvaraj K, Khanam J, Nanda A. Formulation development and statistical optimization of ibuprofen-loaded polymethacrylate microspheres using response surface methodology. Chem Eng Res Design 2015;96:1-14.

8. Deshmukh RK, Naik JB. The impact of preparation parameters on sustained release aceclofenac microspheres: design of experiments. Adv Powder Tech 2015;26:244-52.

9. Wu PC, Huang YB, Chang JS, Tsai MJ. Design and evaluation of sustained release microspheres of potassium chloride prepared by Eudragit. Eur J Pharm Sci 2003;19:115-22.

10. Barzegar Jalali M, Alaei Beirami M, Javadzadeh Y, Mohammadi G, Hamidi A, Andaiib S, et al. Comparison of physicochemical characteristics and drug release of diclofenac sodium Eudragit RS100 nanoparticles and solid dispersion. Powder Technol 2012;219:211-6.
11. Phutane P, Shidhaye S, Lotokar V, Gule A, Sutar S, Kadam V. In vitro evaluation of novel sustained release microspheres of Glipizide prepared by emulsion solvent diffusion evaporation method. J Young Pharma 2010;2:35-9.

12. Hanan M, EL Nanhas. Optimization of eudragit RS microspheres for controlled release of theophylline using response surface methodology. J Pharm Sci Res 2010;2:663-71.

13. Lee JH, Park TG, Choi HK. Effect of formulation and processing variables on the characteristics of microspheres for watersoluble drugs prepared by w/o/o double emulsion solvent diffusion method. Int J Pharm 2000;196:75-83.

14. Sunitha S, Amareshwar P, Santhosh KM. A study on the effect of different cellulose polymers on release rate from tramadol loaded microspheres prepared by emulsion solvent evaporation method. Asian J Pharm Clin Res 2010;3:35-9.

15. Myers RH, Montgomery DC, Anderson Cook CM. Response surface methodology. In: Process and product optimization using designed experiments. 3rd ed. John Wiley and Sons: Hoboken; 2009.

16. Sinko PJ. Martin's physical pharmacy and pharmaceutical sciences. 6th ed. New Delhi: BI Publications Pvt. Ltd; 2006.

17. Tanwar YS, Naruka P, Ojha GR. Development and evaluation of microspheres of verapamil hydrochloride. Braz J Pharm Sci 2006;43:529-34.

18. Trivedi P, Verma AML, Garud N. Preparation and characterization of aceclofenac microspheres. Asian J Pharm 2008;2:110-5.

19. Tayade PT, Kale RD. Encapsulation of water-insoluble drug by cross-linking technique: effect of process and formulation variables on encapsulation efficiency, particle size and in vitro dissolution rate. AAPS Pharm Sci 2004;6:1-8.

20. Arindam H, Biswanath S. Preparation and in vitro evaluation of polystyrene coated microcapsule of the drug-resin complex for achieving prolonged release of diltiazem hydrochloride. AAPS PharmSciTech 2006;7:34-49.

21. Durgapal S, Mukhopadhyay S, Goswami L. Preparation, characterization and evaluation of floating microparticles of ciprofloxacin. Int J Appl Pharm 2017;9:1-8.

22. Augustijns P. In vitro dissolution models for prediction of in vivo performance of oral dosage forms. Eur J Pharm Sci 2014;57:342-66.

23. Raslan HK, Maswadeh H. In vitro dissolution kinetic study of theophylline from mixed controlled release matrix containing HPMC and glyceryl behenate. Ind J Pharm Sci 2006;68:308-12.

24. Zaslavaskaia RM. Controlled release approach to novel multiparticulate drug delivery system. Int J Pharm Pharm Sci 2012;4:757-63.

25. Kilicarslan M, Baykara T. The effect of the drug/polymer ratio on the properties of the verapamil $\mathrm{HCl}$ loaded microspheres. Int J Pharm 2003;252:99-109.

26. Singh S, Arora S, Neelam, Allawadi D. Formulation, optimization and evaluation of sustained release microspheres using Taguchi design. J Pharm Tech Res Mgnt 2014;2:253-64.

27. Malladi M, Jukanti R. Floating pulsatile drug delivery system of Famotidine: design, statistical optimization, and in vitro evaluation. Int J Pharm Pharm Sci 2016;8:169-81.

28. Maiti S, Dey P, Biswanath SA, Ray S. Influence of microenvironmental $\mathrm{pH}$ of alginate facilitated ethyl cellulose microspheres on entrapment efficiency and release characteristics of fluconazole. Int J Curr Pharm Res 2010;2:17-23. 